\title{
Small bowel obstruction due to an enterolith originating in a jejunal diverticulum
}

\author{
P.J. Clarke and M.G.W. Kettlewell
}

John Radcliffe Hospital, Headington, Oxford, OX3 9DU, UK

\begin{abstract}
Summary: A case of small bowel obstruction caused by an enterolith from a jejunal diverticulum is reported. As such diverticula are usually asymptomatic, the diagnosis was not entertained pre-operatively.
\end{abstract}

\section{Introduction}

First described in 1807 by Astley Cooper, the reported prevalence of diverticular disease of the jejunum varies from $1.25 \%$ to $4.6 \%$, depending on the diligence with which the condition is sought (Noer, 1960). This pathological entity is acquired and, although the mechanism of formation is uncertain, it almost invariably involves the proximal jejunum on its mesenteric border. A complication of this condition is described.

\section{Case report}

A 75 year old man was admitted with a $48 \mathrm{~h}$ history of vomiting, colicky abdominal pain and absolute constipation. Examination revealed signs of dehydration, and the abdomen was distended and tympanitic with obstructed bowel sounds. Plain abdominal radiography confirmed small bowel obstruction with a large calcified stone in the right lower quadrant. There was no obvious gas in the biliary tree (Figure 1).

Laparotomy was performed after resuscitation with intravenous fluids, and a stone ( $3 \mathrm{~cm}$ in diameter), was removed from the terminal ileum. The gall bladder was normal and there was no evidence of a cholecystoduodenal fistula. In the proximal jejunum, however, there were multiple diverticula, two of which contained further large stones. One of the diverticula was inflamed and haemorrhagic and it seemed reasonable to presume that the obstructing enterolith had recently been discharged (Figure 2). The larger two diverticula were excised, and the enteroliths removed. His postoperative recovery was uncomplicated.

Correspondence: P. J. Clarke, F.R.C.S.

Accepted: 25 April 1985

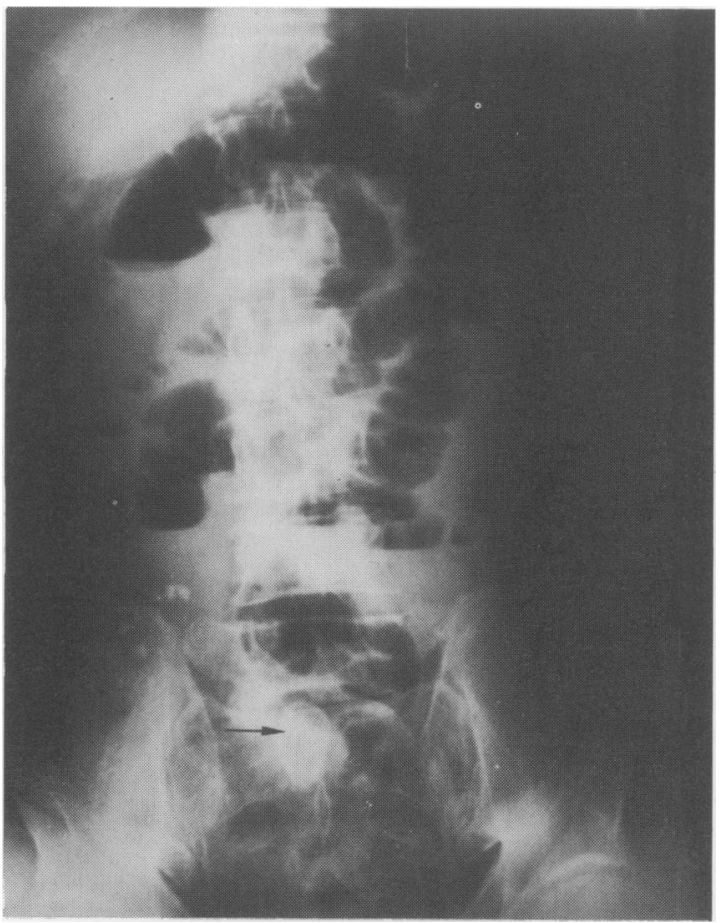

Figure 1 Supine abdominal radiograph showing small bowel obstruction and enterolith (arrow).

\section{Discussion}

Although generally asymptomatic, jejunal diverticula may present with various clinical features. Bacterial overgrowth within diverticula can lead to malabsorption and consequent diarrhoea; inflammation can

(C) The Fellowship of Postgraduate Medicine, 1985 


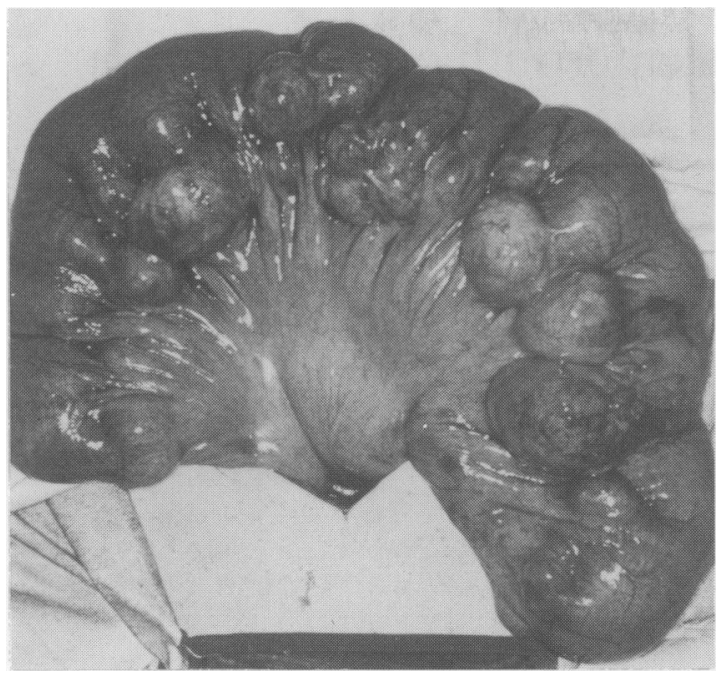

Figure 2 Jejunal diverticulosis. Two further diverticula contained enteroliths.

\section{References}

COOPER, A.P. (1807). In Anatomy and Surgical Treatment of Crural and Umbilical Hernia. p.87. Longman, Hurst, Rees and Orme: London.

NOER, T. (1960). Non-Meckelian diverticula of the small bowel. The incidence in an autopsy material. Acta Chirurgica Scandinavica, 120, 175.

ECKHAUSER, F.E., ZELENOCK, G.B. \& FREIDER, D.T. (1979). Acute complications of jejuno-ileal pseudodiverticulosis: surgical implications and management. American Journal of Surgery, 138, 320. cause diverticulitis which may progress to perforation and subsequent peritonitis; gastro-intestinal haemorrhage can occur. Intestinal obstruction secondary to peridiverticular adhesions, volvulus, diverticulitis, and enterolith formation have all been described (Eckhauser et al., 1979; Williams et al., 1981). An enterolith may cause obstruction to the bowel lumen at the site of the diverticulum, or, as described above, by impaction in the terminal ileum following its release from a diverticulum (Ottinger \& Carter, 1975; Svanes \& Halvorson, 1975).

Gall stone ileus, or obstruction from an ingested foreign body, are more common causes of a radioopaque right iliac fossa stone causing small bowel obstruction. Obstruction from an enterolith formed within a jejunal diverticulum is rare and therefore not usually considered in the pre-operative differential diagnosis. When encountered at operation it seems appropriate to remove any further enteroliths, but resection of lengths of affected jejunum is probably only justified in the presence of acute diverticulitis.

WILLIAMS, R.A., DAVIDSON, D.D., SEROTA, A.I. \& WILSON, S.E. (1981). Surgical problems of diverticula of the smat intestine. Surgery, Gynecology and Obstetrics, 152, 621. OTTINGER, L.W. \& CARTER, E.L. (1975). Obturation of the ileum by a jejunal diverticular enterolith. Gastroen terology, 68, 1596.

SVANES, K. \& HALVORSEN, J.F. (1975). Enterolith obstruction of the ileum as a complication of jejunal diverticulitis. Acta Chirurgica Scandinavica, 141, 816. 